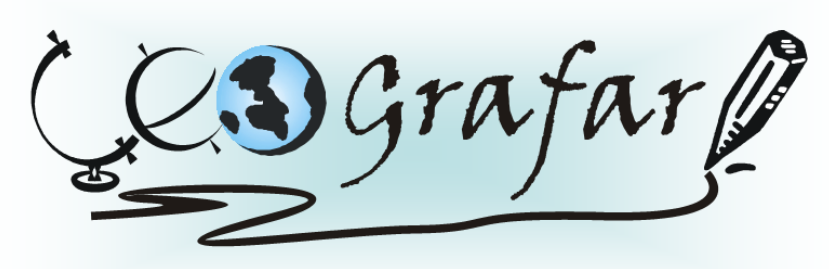

Revista Eletrônica do Programa de Pós-Graduação em Geografia - UFPR

\title{
O CERRADO E A REESTRUTURAÇÃO DO TERRITÓRIO: O CASO DA MICRORREGIÃO DE RONDONÓPOLIS-MT
}

\author{
ROBERTO DE SOUZA SANTOS ${ }^{1}$
}

\begin{abstract}
Resumo: $O$ presente artigo tem por objetivo identificar como as políticas públicas desenharam a organização territorial da Microrregião de Rondonópolis-MT, a partir da introdução do progresso técnico-científico na agropecuária. Aponta que o modelo de desenvolvimento adotado no Mato Grosso no decorrer histórico de sua materialização ocasiona desdobramentos sociais e ambientais e, que o progresso técnico vigente utilizado pela "burguesia do agronegócio" em áreas do cerrado, também ocasiona os mesmos desdobramentos. Levanta uma discussão teórico-crítica sobre o processo de modernização agropecuária na microrregião e, divide historicamente a formação territorial da região em três fases para melhor compreensão desta formação.
\end{abstract}

Palavras-chave: Modernização-agropecuária; Microrregião; Cerrado; Reestruturação do Território.

\section{THE WOODSY AND RESTRUCTURING OF THE TERRITORY: THE CASE OF MICROREGION RONDONÓPOLIS-MT}

\begin{abstract}
This article aims to identify how public policies designed to territorial organization of the microregion Rondonópolis-MT, from the introduction of scientific-technical progress in agriculture and cattle breed. It indicates that the development model adopted in Mato Grosso during its historical expression causes environmental and social developments, the technical force used by the "bourgeoisie of agribusiness" in areas of woodsy, also causes the same developments. It raises a theoretical and critical discussion on the process of agricultural modernization in the microregion and in the area, the formation area, was historically divided into three phases to a better understanding of this formation.
\end{abstract}

Key words: Farming-modernization; Microregion; Woodsy; Reorganization of the Territory.

\footnotetext{
${ }^{1}$ Professor adjunto do curso de Geografia do Campus Universitário de Porto Nacional-TO da UFT e do corpo de Mestrado em Agronegócio e Desenvolvimento Regional da UFT em Palmas. Foi professor substituto no curso de Geografia da UFMT - Campus de Rondonópolis-MT. É autor de dois livros publicados e organizou três livros. Tem artigos publicados na revista do Departamento de Geografia do Campus Universitário de Rondonópolis-MT - UFMT- INTERGEO e no BOLETIM da AGB-SP. Mestre em Planejamento Urbano pela UnB-DF e doutor em Geografia pela UNESP-Rio Claro - SP. Fone: 63-8119-7278. E-mails: robertosantos@uft.edu.br; robertrond@hotmail.com.
} 


\section{INTRODUÇÃO}

Para que se facilite a discussão do tema proposto é necessário debater como era o ecossistema cerrado antes do projeto de modernização agropecuária e também as várias etapas da produção espaço-temporal na microrregião. O cerrado é um ecossistema que se caracteriza pela presença de estrato arbóreo e estrato herbáceo, sendo que ambos representam os seus elementos componentes. Segundo Christofoletti (1979, p. 40-1), para o estrato arbóreo consideram-se as seguintes variáveis: densidade arbustiva (número de árvores/área); intensidade florística (número de espécies/área); distância média entre as árvores; área recoberta pelas copas (por unidade de área padrão); índice de ramificação das espécies; biomassa por área padrão; altura das árvores. Para o estrato herbáceo, pode-se mencionar: altura da cobertura herbácea; área ocupada por esta cobertura; densidade das herbáceas (número de plantas/área); biomassa. Estes são os principais elementos físicos e biológicos do ecossistema cerrado.

No Brasil, a área de cerrado é composta por vários estados: Goiás, Tocantins, Mato Grosso do Sul, região sul de Mato Grosso, oeste e norte de Minas Gerais, oeste da Bahia e Distrito Federal, sendo, portanto, um dos maiores ecossistemas do país. Compartilha com várias espécies de vegetações, como a floresta amazônica, a caatinga e a floresta atlântica e possui uma biodiversidade rica em matas semicaducifólias, que são muito atingidas por queimadas (CONTI; FURLAN, 1995). Caracteriza-se também como uma savana com vegetação arbórea bem esparsa e distingue-se de outras comunidades vegetais do Brasil pela sua fisionomia. Sua vegetação é um mosaico de campos limpos, sujos e cerradão, constituídos de árvores de casca grossa, tortuosas, com plantas xeromórficas que lembram as regiões semidesérticas. As plantas estão adaptadas para retirar água profunda através de raízes que atingem até 15 metros.

Os solos da área são de sedimentos que se originam do Terciário, bastante profundos, azonados, de cor vermelha, porosos, permeáveis e bem drenados, portanto muito lixiviados. São geralmente pobres em nutrientes, devido à sua origem associada a depósitos sedimentares antigos, que vêm sofrendo pedogênese há milhares de anos, conforme explicam Conti e Furlan, (1995). De acordo com as 
diferentes condições geomorfológicas, geológicas e climáticas, os solos dos cerrados variam de textura, estrutura, perfil e profundidade.

Os solos do cerrado brasileiro, além da deficiência em nutrientes, apresentam alta concentração de alumínio, o que determina uma propriedade importante: a capacidade de troca catiônica, fundamental no metabolismo nutricional das plantas. Esta composição química do solo, porém, é muito ácida, devido exatamente à grande presença de alumínio, que é tóxico para a maioria das espécies utilizadas na agricultura. É necessária correção de seu pH (potencial hidrogeniônico) por meio da aplicação de calcário, de preferência o calcário dolimítico, que é um carbonato de magnésio; é preciso, também, fazer adequada adubação. Desta forma, os cerrados tornam-se grandes áreas de cultivo agrícola para exportação e consumo interno. A correção do solo para o plantio mecanizado em grande escala é feita pela adubação com fertilizantes industriais com o uso de tecnologias biogenéticas e recebe o apoio das políticas públicas de investimento regional instituídas especificamente para essas áreas.

Quanto ao relevo, compõe-se de grandes chapadões planos com altitudes entre 300 e 600 metros acima do nível do mar, o que facilita o trabalho mecanizado. Além disso, situa-se geograficamente numa área de grande insolação, fator que contribui para certos tipos de plantio agrícola que requerem esse elemento. $O$ sistema de drenagem, por sua vez, sofre grande influência da topografia, caracterizado por rios permanentes ladeados por matas de galeria e buritizais (CONTI; FURLAN, 1995).

Num segundo momento, é necessário que se faça um debate teórico sobre a noção de território. A noção de território esboçada neste trabalho parte da idéia que ele é constituído por meio das relações sociais, e é por intermédio destas que toda atividade humana se materializa. Neste contexto, entende-se por território um espaço definido e delimitado por e a partir de relações de $\operatorname{poder}^{2}$ (SOUZA, 1995). O território é constituído de relações sociais projetadas no espaço, com a coexistência de relações de poder. Essas relações nascem num dado lugar e para um dado lugar, num dado momento e por uma duração determinada ou indeterminada. Os

\footnotetext{
${ }^{2}$ Rigorosamente falando, o poder não existe; existem sim práticas ou relações de poder; em outras palavras, o poder é uma prática social e, como tal, constituída historicamente (FOUCAULT, 1996).
} 
elementos constitutivos do território são os atores e suas políticas ou o conjunto de suas intenções, isto é, suas finalidades, suas estratégias para conquistar o objeto almejado, os medianos da relação, os diversos códigos e símbolos utilizados, componentes espaciais e temporais utilizados nas relações sociais (RAFFESTIN, 1993).

Para RAFFESTIN (1993), o território é um produto "consumido", ou um produto vivenciado por aqueles mesmos personagens ou atores sociais que, sem haverem participado de sua elaboração, o utilizam como meio. É então todo o problema da territorialidade que intervém permitindo verificar o caráter simétrico ou dessimétrico das relações de poder.

Convém compreender que o território é construído pelos atores sociais e se forma a partir do espaço, ou seja, é o resultado de uma ação racional conduzida por um ator sintagmático (ator que realiza um projeto) em qualquer nível. Ao se apropriar de um espaço, concreta ou abstratamente (por exemplo, pela representação ou pela posse territorial), o ator "territorializa" o espaço. LEFEVBRE citado por RAFFESTIN (1993) mostra muito bem como é o mecanismo da passagem do espaço ao território, "a produção de um espaço físico", balizado, modificado, transformado pelas redes, circuitos e fluxos que aí se instalam: rodovias, canais, estradas de ferro, circuitos comerciais e bancários, auto-estradas e rotas aéreas etc. O território, nessa perspectiva, é um espaço onde se projetou um trabalho e, por conseqüência, revela relações marcadas pelo poder (RAFFESTIN, 1993). Mas o que está em jogo não parece ser apenas o território em si, o espaço físico apropriado ou pretendido, mas a territorialidade como exercício de um domínio que se realiza ou se projeta pelas relações sociais de poder (MARIN, 1993).

Em outras palavras, pode-se afirmar que o território é o espaço político por excelência e o campo de ação dos triunfos (RAFFESTIN, 1993). Nesse viés, a expressão território vem sendo muito utilizada, desde o século XIX, por geógrafos, como por exemplo, Frederico RATZEL, preocupado com o papel desempenhado pelo Estado no controle geopolítico do território, e também por Élisée RECLUS, que procurava estabelecer as relações entre classes sociais e espaço ocupado e dominado.

Numa segunda instância, o território pode ser definido pela relação do homem 
com o meio e com seus símbolos. Estes símbolos são apropriados pelos atores sociais ou por uma classe social dominante que os usa como mecanismos ideológicos para legitimar a identidade territorial. E é por meio destes símbolos (hábitos, traços singulares da sociedade, língua, etc.) que se constrói o discurso regionalista do poder no território. As relações de poder não se limitam somente ao poder ${ }^{3}$ político, econômico e ideológico, mas também incluem o poder simbólico, de acordo com SOUZA (1995). No poder simbólico, o território assume um caráter ideológico à medida que se torna referência para a construção de mistificações geográficas, sendo por isso um instrumento de manipulação política. Além disso, a cada transformação socioespacial, há exigência de uma "renovação" da ideologia e do universo simbólico. Autores como BOURDIEU (1989), CASTRO (1994) e outros fazem essa leitura geográfica a partir do poder simbólico, da representação política e do imaginário social, porém para a abordagem do conceito de região.

Em síntese, é a partir das relações sociais que nascem as relações sociais de poder, e a partir destas é que surge o poder político, econômico e simbólico; o território pode ser construído a partir destes tipos de poder e, estas relações sociais nascem no seio dos conflitos sociais e das lutas de classes sociais.

\section{CERRADO: UM ECOSSISTEMA EM EXTINÇÃO}

Nos parágrafos acima, foi possível visualizar a caracterização deste ecossistema; contudo o cerrado não consiste apenas em um ecossistema composto por vegetais, animais, clima, rede hidrográfica, solo e outros elementos físicos; há também o homem, que se apropria dele e submete-o a transformações com o objetivo de buscar uma paisagem cada vez mais cultural e humanizada. Portanto, o conceito de cerrado como um ecossistema formado somente pelos fatores físicos e biológicos, sem incluir o homem, não é mais válido, a partir do momento em que o cerrado se tornou objeto de apropriação mercantil pela "burguesia do agronegócio".

\footnotetext{
${ }^{3} \mathrm{O}$ poder econômico utiliza a posse de certos bens socialmente necessários para induzir aqueles que não os possuem a adotar determinados comportamentos, como por exemplo realizar o trabalho. $O$ poder ideológico utiliza a posse de certas idéias, valores, doutrinas para influenciar a conduta alheia, induzindo as pessoas a determinados modos de pensar e agir. O poder político utiliza a posse dos meios de coerção social (COTRIM, 2001). O poder simbólico é condicionado pela representação política ou territorial, pelos valores sociais. Por exemplo, a bandeira nacional, o processo eleitoral quando se elegem os representantes municipais, federais, etc.
} 
O processo de "culturalização", isto é, a produção espaço-temporal do território de Mato Grosso, pode ser dividida em quatro fases. A primeira, até 1870 , foi marcada pela presença geopolítica da Coroa portuguesa no controle militar do território, principalmente com a criação da primeira capital de Mato Grosso, Vila Bela da Santíssima Trindade, localizada no sudoeste do estado e fundada no dia 29 de janeiro de 1748, ano em que se criou também a Capitania de Mato Grosso, desmembrada da Capitania de São Paulo. Esta fase também se caracterizou pelas atividades econômicas que visavam a assegurar o controle do território, como por exemplo, a atividade canavieira, que desde 1727 já teria se estabelecido no estado, embora tenha atingido seu desenvolvimento definitivo por volta de 1888 , inclusive com o surgimento das primeiras agroindústrias do açúcar. As principais propriedades territoriais destinadas a essas atividades foram controladas por companhias estrangeiras, como The Brazilian Meat Company, Fomento Argentino SudAmericano, Franco-Brasileira, The Miranda Estancia Company, Sud-Américaine Belge S/A, e The Água Limpa Syndicate, com fazendas entre 5.000 e 884.231 hectares. Agiram na forma de monopólios e tornaram mais intensos os processos de concentração fundiária (BORGES, 1991, p. 62-102). No período, estes atores sociais foram praticamente os donos do poder econômico e político do processo produtivo.

A partir de 1856, com a abertura da navegação através do rio Paraguai, abriuse a possibilidade de produzir o açúcar para exportação em Mato Grosso. Aí, formaram-se grandes propriedades, fazendas de cana-de-açúcar, surgindo uma elite com força política suficiente para se impor no cenário regional e se alternar no poder com os representantes de oligarquias do sul, formadas por pecuaristas e representantes da Companhia Erva-Mate Laranjeira principalmente.

A erva-mate, planta nativa da América já conhecida pelos índios, que a utilizavam como estimulante dos músculos e do sistema nervoso, tornou-se relevante atividade produtiva com a abertura da Hidrovia Paraguai, sendo exportada para a Argentina. Isto possibilitou a criação da Companhia Erva-Mate Laranjeira, que financiou na época a abertura de estradas, hidrovia e pontes e controlou a embarcação do produto, além de ter fábricas para a transformação do referido produto e foi a grande responsável pela construção da ferrovia Noroeste do Brasil, o que permitiu maior integração entre da região e São Paulo (PIAIA, 1997). A atividade 
econômica da erva-mate foi a de maior destaque, do ponto de vista do poder político e econômico no passado de Mato Grosso, de acordo com Silva (1996).

A segunda fase vai aproximadamente de 1870 a 1930. A partir de 1870, a evolução da infra-estrutura ferroviária condicionou grandes transformações econômicas e espaciais na região sul do estado, que passam a incorporá-la ao dinamismo econômico paulista. Tal incorporação proporcionou a intensificação da atividade econômica extrativa e, em conseqüência, Mato Grosso experimentou um outro surto migratório e de povoamento, orientado pela extração da borracha, da ipecacuanha (ou poaia, uma planta medicinal), da cana-de-açúcar e da erva-mate, produtos de grande aceitação no mercado externo na época, informa Piaia (1997). No final do século XIX teve início essa nova fase econômica em Mato Grosso - a da exploração vegetal, baseada, inicialmente, na produção da erva-mate e da poaia e, posteriormente, da borracha. Alguns atores sociais da atividade extrativa vegetal de grande demanda na época, que lidavam no mercado mundial, passaram a selecionar novas porções do espaço geográfico de Mato Grosso, na busca do domínio de sua territorialidade (MOURA, 1983). Além das atividades extrativas referidas, a criação bovina houve também já existia inclusive, com a industrialização do setor, com a introdução do extrato e caldo de carne e do charque, no decorrer de 1920, afirma Borges (1991).

A terceira fase da produção espaço-temporal do território mato-grossense, que se iniciou em 1930 e perdurou até 1970, foi fortemente marcada pela concessão de terras na colonização oficial e doação de glebas no interior do estado. A partir de 1930, as terras devolutas foram vendidas a empresas colonizadoras, e as áreas de colonização oficial ficaram reservadas a pessoas físicas. Neste período, o poder público passou a dimensionar sua estratégia política de colonização e ocupação do território mato-grossense com a privatização de suas terras devolutas e a instalação da colonização dirigida (pública). Foi a partir de 1930, no momento do nascimento e consolidação do capital industrial no Brasil, que Mato Grosso passou a viver uma nova fase econômica e, conseqüentemente, de transformação espacial, com o surgimento de uma força econômica e política da burguesia industrial brasileira, com grande poder político e econômico na organização do território.

Norteado pela política de colonização, o governo estadual, adotou a mesma 
estratégia que fora iniciada por parte do governo federal e, em 1947, de modo a acelerar essa política, criaram-se diversos organismos, cuja atribuição principal era a fundação e organização de colônias agrícolas para o domínio do território (MOURA, 1983). Entre 1939 e 1950, foram criadas na região sul do estado, pelo Departamento de Terras e Colonização (DTC, órgão estadual), as colônias agrícolas estaduais e particulares de Mutum (1939), Paraíso (1943), Nossa Senhora de Fátima (1947), Paulista (1948), Coronel Ponce (1948), Alto Coité (1948), Naboreiro (1949), Macacos (1949) e Rondonópolis (1948), conforme relato de Gontijo (1988, p. 48). Neste período, a ocupação do território se estabeleceu de modo mais racional, com ações políticas dirigidas mais racionalmente, por intermédio das políticas públicas da Marcha para o Oeste.

Para GONTIJO (1988, p. 40-5), esta expressão designou a política de ocupação territorial instituída com a criação de colônias agrícolas, no primeiro mandato do Presidente da República Getulio Vargas, a partir de 1930, devido à necessidade urgente de abrir novas fronteiras econômicas e ampliar a malha viária no Centro-Oeste, com vistas, favorecer a penetração do capital agropecuário na região. Para tanto, incentivou-se a produção na pequena propriedade, que seria responsável pelo abastecimento de grãos na fronteira em expansão, constituída em sua maioria por nordestinos migrados do Sudeste). A Marcha para o Oeste foi um dos condicionamentos da época para a ocupação demográfica e depois econômica do território.

Entre 1950 e 1955, o governo mato-grossense adotou uma política destinada a sistematizar a ocupação das terras e a expansão da fronteira agrícola. De início, o estado incentivou a implantação de empresas colonizadoras particulares, mas não teve êxito, pois as terras colonizadas ficaram inadimplentes, sendo posteriormente, devolvidas ao poder público, explica Demamann (1997). Isto induz a pensar que, quando as coisas não dão certo no capitalismo, o Estado abraça a causa para resolvê-la e restabelecer os interesses da burguesia industrial.

Outro fator de ocupação foi a descoberta do ouro, que deu origem a muitas povoações, localizadas na porção central de Mato Grosso, com a conseqüente ocupação das áreas de cerrado onde se encontraram os veios auríferos. Contudo, este processo acarretou menos destruição do meio ambiente do que a provocada 
pela ocupação atual.

A partir de 1960, iniciou-se a abertura de rodovias e a construção de Brasília, com o objetivo de consolidar a ocupação demográfica, econômica e geopolítica do cerrado. Nos vários ciclos desse processo histórico por meio de ocupações humanas nesta área, aos poucos foi-se transformando de um ecossistema natural em um cerrado de paisagens culturais, com desdobramentos sociais e ambientais.

Neste período, os colonos eram em sua maioria pequenos proprietários, o que permitia a eles, como atores sociais, buscarem sua própria territorialidade. Entretanto, esta busca não é nada fácil: os atores econômicos donos dos meios de produção a bloqueiam. A titulo de exemplo, pode-se observar que, atualmente, um recurso deste bloqueio consiste simplesmente no mecanismo de tirar o emprego do trabalhador por meio da máquina (da robótica), o que dá amplos poderes político aos proprietários dos meios de produção. Em nossos dias, pode-se dizer que as relações de produção apresentam-se mais assimétricas e mais exploradoras do que as de antes.

Finalmente, a quarta fase corresponde ao período a partir de 1970, quando chegaram a Rondonópolis vários imigrantes sulistas à procura de terras mais baratas, como as do cerrado, que na época eram comercializadas a preços baixíssimos, o fato que thes permitiu adquirir grandes áreas de terra a um pequeno custo. Isto significa que a venda de suas terras no sul, por menor que fosse o preço, daria para comprar imensos imóveis nas áreas de cerrado, principalmente com o apoio financeiro do poder público, por meio das políticas públicas de investimento no Planalto Central. Juntamente com os "gaúchos" ${ }^{4}$, chegaram ao cerrado os tratores, máquinas e instrumentos industrializados para a agricultura de precisão.

As primeiras terras a ser ocupadas foram as "terras de cultura" (áreas de mata), que não precisavam de tecnologia industrial para obter produtividade e tinham solos mais "férteis". Mas, após 1970, chegou à região toda uma infraestrutura de equipamentos industrializados, e teve início a "despecuarização espacial" ${ }^{5}$, quando os agentes econômicos colocaram a agricultura e a pecuária

4 Popularmente, diz-se gaúchos, na região, em referência a todos os que chegaram do sul: paranaenses, catarinenses e os verdadeiros gaúchos, do Rio Grande do Sul.

50 processo de "despecuarização espacial", aqui no texto, diz respeito à valorização excessiva, por parte das políticas públicas, do investimento na agricultura, colocando em segundo plano as políticas 
mecanizada em primeiro plano e a tradicional em segundo lugar. Nos dias atuais, a ocupação do espaço local é explicitamente econômica e é denominada, na presente discussão teórica, de ocupação econômica do território, nesse processo, este é objeto de um poder central comandado pelos atores econômicos que, ao mesmo tempo, controlam todo o processo produtivo regional, impondo sua racionalidade de crescimento econômico. Vale lembrar que as atividades de extração vegetal e mineral, antes dos anos 70, mesmo no cerrado ou nas áreas de "terras de cultura", não causavam muita agressão à natureza. Atualmente, pelo contrário, há estimativas de que restam apenas $20 \%$ do ecossistema do cerrado.

Na Microrregião de Rondonópolis-MT, a reestruturação do território implicou uma profunda forma de olhar filosoficamente o processo produtivo, com fortes mudanças nas relações sociais de produção e ao meio ambiente. A partir do momento em que o homem "pós-moderno" se inseriu no cerrado por intermédio de seus instrumentos técnicos, pode-se afirmar que esta área passou a ser um "espaço instrumentalizado", tornando-se a grande responsável pela produção de grãos no cenário nacional. A conquista do cerrado foi a grande invenção dos trópicos no século $X X$.

Quanto à formação do espaço geográfico do ponto de vista da produção espaço-temporal especificamente na Microrregião de Rondonópolis, Monteiro (2004) considera que a análise desse processo permite estabelecer três períodos. 0 primeiro período de colonização vai de 1902 a 1930; corresponde ao período inicial, quando no antigo território havia a etnia Bororo. Em agosto de 1915, foi promulgado o Decreto-Lei $n^{\circ} 395$ pelo governo do Mato Grosso, determinando a doação de 2.000 ha destinados à formação do patrimônio de Rio Vermelho, denominação que perdurou até 1919, quando, em homenagem ao Marechal Rondon, passou a denominar-se Rondonópolis. Mas o povoamento de fato teve início a partir de 1940, quando, com as políticas da Marcha para o Oeste, começou a se estruturar a fronteira agrícola.

O segundo período de colonização corresponde à implantação das colônias, entre 1947 e 1960, coincidindo com a chegada dos pecuaristas. Foi uma época em que o poder público doou terras para colonos por intermédio da colonização pública 
e privada. Nestes programas, criaram-se Jaciara, Rondonópolis e Poxoréo. Em 1947 deu a criação da rodovia Cuiabá - Campo Grande, que permitiu o acesso de novos migrantes à aquisição de terras na região. Entre 1950 e 1960, chegaram pecuaristas mineiros e paulistas, que adquiriram grandes fazendas. Neste surto migratório começou o processo de pecuarização. A proporção entre o preço da terra em São Paulo e em Rondonópolis era, na época, o equivalente a 7 a 8 por 1: cada alqueire na região do Vale do Paraíba correspondia a 7 a 8 em Rondonópolis, isso nas zonas de "terras de cultura" e, no caso das áreas do cerrado, o preço era consideravelmente menor. O sistema de arrendamento foi um regime de exploração agrícola muito utilizado nesta fase.

O terceiro período foi marcado pela passagem da agricultura tradicional para uma agricultura e uma pecuária profissionalizada e mecanizada. Por volta de 1970 ocorre a chegada de um novo ator, que mudaria totalmente a concepção da produção agropecuária, com um novo perfil de produtor, por meio de novas tecnologias e gerenciamento, culminando em mudanças na organização do território.

Ainda se pode analisar a produção espaço-temporal da região por meio da fronteira, pois esta organiza e estrutura o território no espaço-tempo em Mato Grosso. De acordo com Diniz (2003), a fronteira pioneira representa os assentamentos pioneiros caracterizados pela ausência de mercados de terra e de trabalho, por rápido crescimento populacional via imigração e por grande disponibilidade de terra.

Há também o caso das fronteiras urbanizadas, que fazem parte de uma herança dos embrionários núcleos urbanos criados no coração dos projetos de colonização, muito freqüentes na região amazônica e em Mato Grosso, que integra essa região. Seu crescimento é condicionado pelo processo de evolução das áreas de assentamento circunvizinhas, tornando-se, portanto, entidades inseparáveis dos projetos agrícolas dos quais se originaram. Os núcleos urbanos de Pedra Preta, Juscimeira, Jaciara e São Pedro da Cipa são parte destes projetos na microrregião. As transformações estruturais no seu entorno intensificam os movimentos ruralurbanos, aumentando o tamanho e a complexidade dos núcleos. Estes podem crescer o suficiente nessa complexidade e na organização a ponto de se tornarem 
novos municípios ${ }^{6}$. Esses lugares constituem centros de concentração e redistribuição de mão-de-obra, formada por ex-colonos e migrantes que não conseguiram acesso à terra. À medida que os centros ganham dinamismo, eles tendem a receber também migrantes oriundos de áreas urbanas, atraídos pelo crescente setor terciário, como é o caso da cidade de Rondonópolis. Nestas áreas, o desejo de adquirir terra ainda é um importante estímulo à imigração.

$\mathrm{Na}$ microrregião, a fronteira agrícola mecanizada encontra-se, teoricamente, em um estágio de mecanização avançado, no qual os núcleos urbanos se estruturaram a partir dos projetos de colonização. Em outras palavras, o processo de reestruturação territorial da Microrregião de Rondonópolis caracteriza-se atualmente por uma "fronteira urbanizada". Por outro lado, pode-se dizer que, até 1970, a ocupação do território em termos locais era uma questão de segurança nacional, geopolítica e demográfica, mas a ocupação econômica e a efetiva integração econômica de Mato Grosso no cenário internacional verificaram-se posteriormente, a 1970.

Esta fronteira urbanizada fez da cidade de Rondonópolis uma cidade-região na Mesorregião Sudeste Mato-grossense. Segundo Rosso (1999), a influência da cidade de Rondonópolis na malha urbana desta mesorregião é fato cristalizado, pois aí, se concentra grande parcela das atividades comerciais, econômicas e de prestação de serviços circunscritas no espaço desta, principalmente aquelas revestidas de um elevado conteúdo técnico. Nos dias de hoje, a Microrregião de Rondonópolis constitui uma região polarizada dentro do sudeste mato-grossense e, ao mesmo tempo, conseguiu estabelecer uma área de influência em seu entorno imediato, o que a caracterizou como uma cidade-região e tornou-a um centro que coordena e dirige as atividades de produção. Isso permitiu uma série de funções em relação às demais cidades da microrregião. É importante ressaltar que essa pujança da cidade de Rondonópolis é um desdobramento do vigente processo de modernização agropecuária.

Diante o exporto acima, pode-se fazer alguns questionamentos. Como era o ecossistema cerrado antes do processo de modernização da economia na Microrregião de Rondonópolis? Acredita-se que era constituído pela presença de

6 Como é o caso de São José do Povo na microrregião, emancipado no início dos anos 90. 
grandes áreas naturais pouco devastadas, e a ocupação humana dava-se, principalmente, nas áreas de extração mineral. Os meios de produção utilizados nas áreas de "terras de cultura" ou nas áreas de cerrado proporcionaram menos implicações geoambientais do que os atuais? A antiga exploração da terra baseavase em instrumentos rudimentares, de baixo poder destrutivo do ecossistema, como por exemplo a roça de toco, que utilizava a enxada; por outro lado, admite-se que o desmatamento baseado em machados e motosserra é muito lento. Ao contrário do desmatamento efetuado atualmente por tratores ${ }^{7}$ detona dezenas de hectares em poucas horas. No solo não eram colocadas quaisquer substâncias químicas, e não havia a adoção intensiva de defensivos agrícolas nem de herbicidas, que são prejudiciais ao ecossistema. Por último: Racionalmente, a ação social dos atores da antiga economia microrregional tinha os mesmos ingredientes político-econômicos dos atores sociais da atualidade? Nos dias atuais, os atores econômicos acionam o seu território de modo mais racional, são mais articulados politicamente e dispõem de uma ação social eficaz, com objetivos definidos, condicionada pelo conhecimento técnico-científico, segundo análise de Weber (2002). Além do mais, atualmente, é por intermédio deste conhecimento que se criam as condições ideais para a busca da mais-valia. Destaca-se, ainda, que o presente trabalho parte do pressuposto de que a ocupação econômica aconteceu, efetivamente, a partir de 1970, por meio de novas formas racionais e pela utilização do conhecimento técnico-científico.

\section{REESTRUTURAÇÃO DO TERRITÓRIO}

Convém frisar que a palavra reestruturação evoca uma combinação seqüencial de desmoronamento e reconstrução, de desconstrução e tentativa de reconstituição, proveniente de algumas deficiências ou perturbações nos sistemas de pensamento e de ação aceitos, tanto no tempo como no espaço. Os períodos de crise são também de dramática reestruturação. O capitalismo está sempre transformando o espaço à sua própria imagem, mas em períodos de expansão, isto significa a

7 No Centro-Oeste, nas áreas de cerrado, utiliza-se intensamente o trabalho mecanizado, por meio de tratores, para o desmatamento. Às vezes, utilizam-se dois tratores, com uma corrente bastante resistente. Os tratores ficam lado a lado, tendo entre eles uma faixa de vegetação, que pode ter vários metros de largura; quando os tratores se deslocam, a corrente vai sendo arrastada, arrancando todas as árvores que encontrar pela frente. 
substituição de padrões mais ou menos estabelecidos num período anterior (SMITH, 1988).

O momento contemporâneo pode ser considerado, a mais recente tentativa de reestruturar as matrizes espaciais e temporais do capitalismo na busca de um “arranjo" espaço-temporal voltado para a sua sobrevivência (SOJA, 1983). Diz-se reestruturação do território, porque em todo território, antes já existe alguma estrutura que o próprio capital construiu para sua sobrevivência e, num determinado momento, para que ele continue sobrevivendo, torna-se necessário que se reorganize o "arranjo" espacial ou se estabeleça uma nova organização na divisão internacional do trabalho.

Isso implica dizer que a reestruturação do território seria uma das formas de buscar respostas favoráveis à reprodução do modo de produção. Nestes termos, a reestruturação traduz-se num projeto resultante de uma escolha determinada e racionalizada, de compreender, organizar e transformar a realidade no território, num processo em que a escolha, inicial define o âmbito das possibilidades, para evitar possibilidades alternativas que são incompatíveis com ela (MARCUSE, 1973).

Partindo desta linha de raciocínio, percebe-se que na Microrregião de Rondonópolis-MT, o processo de reestruturação do seu território constituiu-se, um projeto arquitetado pelos atores poder público e "burguesia do agronegócio", por intermédio da ciência, da técnica e das políticas públicas de investimento. Nesse processo, verifica-se que estas políticas públicas atenderam as necessidades da reprodução ampliada do capital industrial por meio de incentivos fiscais e financiamentos.

\section{OCUPAÇÃO DO TERRITÓRIO E REESTRUTURAÇÃO ESPACIAL DA MICRORREGIÃO DE RONDONÓPOLIS}

Teoricamente, o termo ocupação do território não indica somente ocupação baseada na incorporação de novas terras ao processo produtivo ou aquela de caráter econômico ou demográfico, mas também a apropriação do espaço geográfico que é cristalizada pelo movimento, ou seja, que é um processo e, ao mesmo tempo, pressupõe que o território sempre é objeto de ocupação e 
apropriação pelos atores sociais "burguesia do agronegócio" e poder público em Mato Grosso no momento atual. Esse território é posse de ator(es) social(is), cristalizada e espacializada pelas relações sociais de poder deste(s).

Neste artigo, compreende-se a ocupação econômica como sendo os desdobramentos das políticas públicas de investimento estabelecidas a partir de 1970, que tiveram como objetivo explícito construir na região condições altamente favoráveis para a reprodução ampliada do capital, sem esquecer que estas políticas se estabeleceram de uma forma racional sintonizada com um empreendimento técnico-científico a partir de um projeto desenvolvimentista. Isto não significa dizer que as políticas públicas de investimento antes de 1970 eram desprovidas de uma preocupação com o crescimento econômico, mas que tais políticas, entre 1940 e 1970, explicitaram como foco o estabelecimento de uma infra-estrutura básica, com ações tais como a construção de rodovias, de pontes, a criação de núcleos urbanos (projetos de colonização) entre outras, para dar sustentabilidade à reprodução do capital, tendo como objetivo principal a consolidação da integração nacional e a ocupação demográfica com vistas à manutenção do território. No entanto, a partir da década de 70, as políticas públicas de investimento se tornam mais explícitas no que diz respeito à ocupação econômica do cerrado mato-grossense.

Neste contexto, pode-se observar que, no Mato Grosso, a partir de 1970, o capital, com o apoio do Estado, reestruturou o território com novos elementos como a introdução do conhecimento técnico-científico na produção agrícola no cerrado e a integração da indústria à agricultura, para atender a uma demanda do mercado internacional e à dinâmica da balança comercial brasileira. Em conseqüência, a microrregião foi homogeneizada internamente, com a predominância de uma das formas do capital, neste caso a agropecuária mecanizada, como raciocina Oliveira (1977).

No processo de formação e reestruturação espacial da microrregião, as políticas públicas de investimento constituíram condicionamentos significativos no sentido de favorecer o imigrante a territorializar-se em Rondonópolis-MT. Isto indica que a ação do Estado consolida a reprodução social dos espaços regionais por meio de sua competência política de planejar o território, tanto o urbano como o rural. As políticas públicas propiciam condições favoráveis não somente para a reprodução 
social do espaço, mas, sobretudo, para a reprodução econômica do território. Assegura as condições ideológicas quando se trata da unidade e da "coesão territorial", isto é, contribui para que os indivíduos reconheçam seu espaço vivenciado e percebido. Não se pode esquecer que o processo de produção do território é determinado pela infra-estrutura econômica, mas regulado pelo jogo político, o que implica na apropriação do espaço pelo ator social que então territorializa esse espaço (BECKER, 1983). Nestas condições, território é tanto um instrumento quanto um produto do "capitalismo nacional", no caso brasileiro, por meio das estratégias espaciais implícitas e explícitas do Estado. O objetivo desta ação intervencionista é a manutenção e expansão em larga escala da produção e reprodução privada do espaço geográfico. Quer dizer, faz-se investimentos públicos para o enriquecimento cada vez maior de uma fatia da sociedade mato-grossense que se pode denominar de "burguesia do agronegócio".

No processo de modernização das áreas agrícolas na porção central do Brasil, a política nacional-desenvolvimentista, aliada aos investimentos públicos em infraestrutura, entre 1968 e 1980, condicionou a expansão agrícola e a ocupação do cerrado e, sobretudo, procurou integrar os "espaços vazios" do Brasil Central e da Amazônia ao capitalismo do Sul-Sudeste. Determinadas áreas do cerrado foram, em maior ou menor grau, atingidas por políticas e programas governamentais de ação direta sobre a região ou sobre algumas de suas áreas, o que criou condições para a expansão de frentes de agricultura comercial, camponesa e especulativa, contribuindo para a intensificação da atividade econômica (MARTINS; ALHO, 1995).

A necessidade de novas atividades econômicas é uma característica do processo de produção e reprodução do espaço geográfico no atual regime de acumulação, no qual cada formação econômico-social procura organizar o território à sua maneira, de acordo com os interesses do grupo dominante e suas disponibilidades de técnica e ciência e de capital. Sendo assim, as transformações atuais que se verificam no espaço agrário brasileiro constituem o reflexo da política de modernização da agricultura aplicada pelos governos após a década de 50 .

Para isso, foram fundamentais os programas de incentivos e investimentos, tais como o POLONOROESTE (Programa de Desenvolvimento Integrado do Noroeste Brasileiro) concebido como um programa de desenvolvimento regional para ser 
implantado nas áreas cortadas pela BR-364 (Cuiabá - Porto Velho); o POLOCENTRO (Programa de Desenvolvimento dos Cerrados), instituído por meio do Decreto $n^{\circ} 75.320$ de 29/01/75, com o objetivo básico de conquistar o cerrado, atingindo frações territoriais goiana e mato-grossense (OLIVEIRA, 1991); o PRODECER (Programa Nipo-Brasileiro de Desenvolvimento Agrícola da Região dos Cerrados), do governo Ernesto Geisel, que resultou de um convênio com o Japão, em 1976; a SUFRAMA (Superintendência da Zona Franca de Manaus); o PROTERRA (Programa de Redistribuição de Terras e Estímulo à Agroindústria do Norte e Nordeste) instituído em 06/07/1971 pelo General Médici, cujos objetivos eram promover o fácil acesso do homem à terra e criar condições de emprego e de mão-de-obra; o POLAMAZÔNIA (Programa de Pólos Agropecuários e Agrominerais da Amazônia), que veio para territorializar os grandes monopólios na Amazônia, com a finalidade de promover 0 aproveitamento integrado das potencialidades agropecuárias, agroindustriais, florestais, em áreas prioritárias da Amazônia; a SUDAM (Superintendência de Desenvolvimento da Amazônia), que foi denominada de "desenvolvimento regional e desenvolvimento nacional", e baseou-se na ideologia da "segurança e desenvolvimento" da Escola Superior de Guerra; o PIN (Programa de Integração Nacional), criado em 1970; o PRODOESTE (Programa de Desenvolvimento do Centro-Oeste), instituído na década de 80; a MATEMAT (Companhia Mato-Grossense de Mineração), que foi criada em 1976, com objetivo de fomentar a exploração, industrialização, transporte e exportação dos recursos minerais no estado (e funciona até hoje); a CODEMAT (Companhia de Desenvolvimento de Mato Grosso), a qual procurou criar uma infra-estrutura em áreas já ocupadas e incentivar a ocupação das áreas de fronteiras e a integração do território estadual; o PROMAT (Programa Especial de Desenvolvimento do Estado de Mato Grosso), que visava dar apoio básico de infra-estrutura econômica e social ao estado, após a redivisão territorial e o PRODEI (Programa de Desenvolvimento Industrial de Mato Grosso).

Os resultados das políticas de implantação destes projetos foram marcados pelo favoritismo, pois o dinheiro público foi usado para beneficiar grupos privilegiados, o que acarretou a formação do espaço agrário estadual, com a terra sendo transformada em objeto mercantil de enriquecimento de alguns empresários (PIAIA, 1997). Em geral, estes programas constituíram verdadeiros "agentes" que 
promoveram a reestruturação territorial da microrregião.

Importa salientar, ainda, que a atuação das políticas de investimento e dos programas de fomento à agropecuária no Cerrado Central se estabeleceu territorialmente com o auxílio de uma parafernália político-ideológica. Trazendo este enfoque para a área em estudo, constata-se que na sua reestruturação territorial, o discurso político-ideológico desempenhou papel fundamental. Primeiro, esse discurso esteve impregnado nas políticas públicas de colonização de 1930, com o lema "Marcha para o Oeste" (do governo Getúlio Vargas) acompanhado de uma forte propaganda nos meios de comunicação da época, alegando que a migração para o Oeste seria uma ótima opção para o cidadão/migrante.

Posteriormente a 1970, o discurso foi sustentado por uma engenharia políticoideológica denominada de "modernização", a qual modernizou os diversos setores da economia, enquanto o Programa de Integração Nacional (PIN) trouxe todo um discurso com o lema "Integrar para não Entregar", instituído pelos governos militares com o objetivo de povoar o Norte e Centro-Oeste brasileiro. Na microrregião, este projeto de modernização pode ser pensado, teoricamente, enquanto um discurso ou ser traduzido como um mecanismo político-ideológico que se cristaliza e territorializa por intermédio desse mesmo discurso. Este se evidenciou a partir de 1966, quando a ditadura militar (instaurada em 1964 e encerrada em 1985) pôs em prática um amplo programa de ocupação econômica da Amazônia brasileira, em bases supostamente modernas, com objetivos econômicos, mas, sobretudo geopolíticos, segundo análise de Martins (1997).

A Amazônia Legal constitui um exemplo cristalino deste raciocínio: é uma região construída por um recorte espacial no conjunto de várias unidades federativas, por meio de decretos, e consubstanciada pelas políticas públicas de investimento provenientes da SUDAM, PNDs, PDAs, os quais alocaram recursos financeiros para sua concretização. Pode-se afirmar que este discurso ${ }^{8}$ originário dos planos governamentais desenhou toda uma espacialidade regional chamada Amazônia Legal. Como Mato Grosso foi integrado ao território da Amazônia Legal, em 1972, é coerente admitir-se que a Microrregião de Rondonópolis-MT também é

8 Inclusive com ampla a utilização de propaganda nas emissoras de rádio, principalmente a Rádio Nacional localizada em Brasília-DF, com fortes incentivos publicitários visando à consagração da Amazônia Legal. 
uma espacialidade resultante do mesmo processo. Tal discurso é um dos ingredientes político-ideológicos que busca respostas eficazes perante ao mercado globalizado, porém fragmentado com acirrada concorrência. A partir deste cenário, o capital agropecuário rondonopolitano sente a necessidade de se reestruturar o seu espaço produtivo a partir de 1970.

Por outro lado, o processo de colonização na Amazônia Legal tem uma especificidade: a frente pioneira da corrente migratória constituída pelo gaúcho, que resultou na cristalização de um imaginário social na Amazônia semelhante ao de sua origem. Criou-se na Amazônia Legal uma imagem do "gaúcho pioneiro", veiculada pelos meios de comunicação responsáveis pela divulgação do processo de colonização, quando se procurou, sobretudo, consumar a legitimação simbólica das atividades econômicas e políticas que ele antes exercia nas regiões de origem, nos locais de colonização, afirma Goettert (2000). Este imaginário faz parte também da frente de expansão, na qual é notório o predomínio dos valores sociais, das crenças e culturais na definição e sustentação dos vínculos sociais que se territorializam pela mediação do discurso político-ideológico (MARTINS, 1997).

Numa segunda instância, quando se faz uma análise da reestruturação econômica e espacial na microrregião, percebe-se que ela vem acoplada a um adicionante ideológico que é fruto da ideologia desenvolvimentista, que se resume na criação de um imaginário social e político na expansão da fronteira agrícola mecanizada no estado de Mato Grosso, pelo menos no atual momento histórico. Tal fenômeno é um mecanismo político-ideológico que tem a finalidade de intensificar mais ainda o processo de migração para a região, com vistas a cristalizar a ocupação do território e, sobretudo, condicionar o crescimento econômico.

Segundo Cardoso (1978), anteriormente aos anos 1970, o imaginário social resultante das políticas públicas da Marcha para o Oeste e de integração nacional funcionou como condicionamento para a efetivação da frente pioneira integrada por goianos, paulistas e nordestinos, quando a ideologia desenvolvimentista estabeleceu-se com o discurso de que o desenvolvimento construído pelos pioneiros seria de todos, indistintamente. De acordo com a sua própria formulação, a ideologia do desenvolvimentismo se propôs despertar a consciência para a necessidade do desenvolvimento, construindo inclusive uma "nova mentalidade" e promovendo "o 
espírito do desenvolvimento". Goettert (2000, p. 43) relata ainda, que o fenômeno migratório para Rondonópolis a partir de 1970:

(...) reforçava-se, no imaginário social, a concepção de que o desenvolvimento construído pelos pioneiros seria condição para 0 desenvolvimento de todos, possibilitando o acesso à renda, às benesses do progresso. Expandia-se, assim, o mito do pioneiro no imaginário social como parte vital da legitimação ou definição de identidades sociais, culturais e políticas.

Vale lembrar também, a partir de 1970, grande parte desse processo deu-se por intermédio do imigrante sulino capitalizado, quando se construiu no contexto regional um imaginário social com o significado de prosperidade e de êxito baseado numa concepção homogeneizadora dos sulistas em Rondonópolis, que serviu a uma ideologia para a sustentação da elite econômica e política. Este imaginário social objetivado e percebido pelo imigrante sulino desenhou uma nova territorialidade na Microrregião de Rondonópolis-MT, aquela do mundo próspero, do futuro, da própria territorialidade de costumes do sulino adicionada a um imaginário social em que 0 crescimento, o progresso econômico e social é percebido ideologicamente como real.

Da mesma forma, cabe aqui enfatizar que este imaginário social, político e territorial também se consolidou por meio de um comportamento não racional, que Weber ${ }^{9}$ convencionou de "a ação tradicional", enquanto que as políticas públicas de investimento se caracterizariam por uma ação racional.

$\mathrm{Na}$ construção deste imaginário, o Cerrado Central constituiu um bom atributo natural de que tanto o Estado como a "burguesia do agronegócio" se apropriaram, com o intuito de tornar a natureza um recurso político não apenas por sua utilidade, mas como ela é percebida simbolicamente. Os recursos disponíveis da natureza constituíram suporte fundamental para 0 desenvolvimento econômico da microrregião. Esse recurso político racionalizado e objetivado, na verdade, traduziuse na efetivação de imagens construídas socialmente como base fundamental do

9 "A ação tradicional é aquela ditada pelos hábitos, costumes e crenças, transformada numa segunda natureza. Para agir de conformidade com a tradição, o ator não precisa conceber um objetivo ou um valor, nem ser impelido por uma emoção; obedece simplesmente a reflexos enraizados por longa prática" (WEBER apud ARON, 2000, p. 449). 
imaginário social, principalmente para o imigrante sulista capitalizado, que foi motivado a investir na região por este imaginário social e, simultaneamente, constituiu-se num recurso para a retórica e ação para a política local.

Tal fenômeno pode ser compreendido como a relação entre a natureza e o imaginário político que define uma abordagem na busca de compreender formas possíveis de utilização de aspectos particulares da natureza, para a construção do imaginário coletivo de uma sociedade e a instrumentalização deste imaginário com vistas a ações de base política no território, quando o imaginário político torna-se imaginário territorial (CASTRO, 1997).

Isto significa que o poder público, por meio de suas políticas, juntamente com a "burguesia do agronegócio", apossaram-se destes atributos para implantar o processo de mecanização e de "ideologização" da natureza (cerrado). Em outras palavras, pode-se dizer que estes atores sociais construíram no espaço geográfico da Microrregião de Rondonópolis-MT a sua própria espacialização, que começou a materializar-se a partir d e 1970, quando houve uma intensa mecanização do seu território, ou seja, a "artificialização do espaço natural", a qual contribuiu para a criação da espacialidade territorial capitalista.

As atividades sociais e econômicas, sejam elas provenientes do poder público ou dos atores econômicos, constituem-se então em processos que se manifestam espacialmente, mas trazem no seu bojo a capacidade de determinar e de ser determinadas pelo poder político-ideológico e simbólico (CALIXTO, 2001). Como exemplos, têm-se o Estado, que começou a planejar o desenvolvimento industrial por meio das políticas públicas de investimento para a consolidação do território nacional, num crescente recurso simbólico para a legitimação do Estado e, atualmente, o discurso da "burguesia do agronegócio", quando alega que as condições naturais podem determinar o progresso, que o Cerrado Central constitui o "celeiro do planeta" ${ }^{10}$.

Este "espaço geográfico racionalizado e mecanizado" faz parte de uma

10 Por volta de abril e maio de 2004, um órgão da imprensa local (TV Centro América) instituiu um programa transmitido aos sábados, no qual ventilou a informação de que a produção mecanizada de soja e outros produtos agrícolas no Mato Grosso constituem uma grandeza extraordinária, a ponto de transformar a região em um celeiro do planeta. Este programa não surgiu do nada, mas sim em função da necessidade de se criar um imaginário social na região que se traduza no progresso, na região do desenvolvimento e do crescimento econômico. 
fronteira que constitui um instrumento político-ideológico no sentido de conter as tensões e conflitos sociais da população no território, quando esta é expropriada de suas terras e migrada para uma região de povoamento rural ou urbano. Ao mesmo tempo, atua como fator que contribui e proporciona a urbanização de áreas pouco povoadas para assegurar a reprodução do capital, por meio da abertura de novas áreas e da criação de núcleos urbanos como ponta de lança para a ocupação territorial (BECKER et al., 1990).

\section{CONSIDERAÇÕES FINAIS}

O modelo de desenvolvimento adotado para a reestruturação espacial da microrregião, articulado ao mercado internacional globalizado, parte da filosofia de que o crescimento econômico contínuo é a única forma de buscar a qualidade de vida, de desenvolvimento social, de criar mais empregos e justiça social. Do ponto de vista dos seus desdobramentos sócio-ambientais também é questionável. A sua lógica econômica é intrinsecamente incompatível com a ética ecológica, porque nesta, não há espaço para os valores da sociedade industrializada de consumo.

Este modelo de desenvolvimento desemboca no racionalismo utilitarista e prega o reducionismo econômico como medida única para viabilizar os propósitos do mercado, desenvolvida sob a lógica da competição. Este raciocínio pressupõe dizer que haja uma associação da racionalidade econômica com a lógica competitiva, uma vez que os imperativos do mercado são racionais e, por si mesmos, capazes de organizar a vida econômica, social e política.

O processo de modernização no território parte de um projeto filosófico de conteúdo positivista, que em suas etapas sucessivas adquire um conteúdo científico, técnico-científico e, depois, quando manipulado por um agente social, adquire um conteúdo político-ideológico. Nesse processo, o poder econômico, político-ideológico e simbólico entram como variáveis condicionantes do processo de modernização no território.

Este modelo de desenvolvimento é conservador, não induz a uma discussão teórico-crítica que questione a alta concentração fundiária, da riqueza concentrada nas mãos de uma minoria de pessoas, dos valores sociais pré-estabelecidos e, 
sobretudo desconhece uma sociedade composta de classes sociais diferentes em que uma apropria da riqueza gerada e as outras continuam a margem. Não propõe uma reforma agrária socialmente justa, pelo contrário, estabelece um terreno fértil para a reprodução eterna da estrutura fundiária desenhada desde o Brasil colônia.

\section{REFERÊNCIAS}

ARON, Raymond. As etapas do pensamento sociológico. São Paulo: Martins Fontes, 2000.

BECKER, Bertha K.et al. Fronteira amazônica: questões sobre a gestão do território. Brasília: Editora da UnB, 1990.

BECKER, Bertha K. O uso político do território: questões a partir de uma visão do Terceiro Mundo. In: BECKER, Bertha K. et al. (orgs.). Abordagens políticas da espacialidade. Rio de Janeiro: UFRJ, 1983.

BOURDIEU, Pierre. O poder simbólico. Rio de Janeiro: Bertrand Brasil, 1989

BORGES, Fernando Tadeu de Miranda. Do extrativismo à pecuária: algumas observações sobre a história econômica de Mato Grosso (1870 a 1930). Cuiabá: Universidade Federal de Mato Grosso, 1991, p-62-102.

BOYER, Robert. La politique à l'ére de la mondialisation et de la finance: le point sur quelques recherches régulationistes. In: BOYER, Robert. L'année de la régulation: économie, institutions, pouvoirs. État et politique économique. volume 3. Paris: La Découverte, 1999.

CALIXTO, Maria José Martinelli Silva. As articulações político-ideológicas do poder público no processo de (re)definição da diferenciação sócio-espacial. Boletim Paulista de Geografia- AGB. São Paulo, 2001.

CARDOSO, Miriam Limoeiro. Ideologia do desenvolvimento - Brasil: JK-JQ. $2^{\mathrm{a}}$ ed. Rio de Janeiro: Paz e Terra, 1978.

CASTRO, Iná Elias. Imaginário político e território: natureza, regionalismo e representação. In: CORREIA, Roberto Lobato et al. (orgs.). Explorações geográficas: percursos no fim do século. Rio de Janeiro: Bertrand Brasil, 1997.

CHRISTOFOLETTI, Antônio. Análise de sistemas em Geografia. São Paulo: Hucitec, 1979.

CONTI, José Bueno; FURLAN, Sueli Ângelo. Geoecologia: o clima, os solos e a biota. In: ROSS, Jurandy L. Sanches (org.). Geografia do Brasil. São Paulo: Edusp, 1995.

COTRIM, Gilberto. Fundamentos da filosofia: história e grandes temas. $15^{\mathrm{a}}$ ed. São Paulo: Saraiva, 2001. 
DEMAMANN, Mírian Terezinha Mundt. O avanço da fronteira agrícola e a redivisão territorial do sudeste mato-grossense. Instituto de Ciências Humanas e Sociais, Coletânea $n^{\circ}$ 02, UFMT- Campus Universitário de Rondonópolis-MT, 1997.

DINIZ, Alexandre M. A. Migração na fronteira agrícola. In: AGETEO. Volume 28, $\mathrm{n}^{\circ}$ 03, setembro/dezembro 2003.

FOUCAULT, Michel. Microfísica do poder. 12 ed. Rio de Janeiro: Graal, 1996

GOETTERT, Jones Dari. "O Vôo das Pandorgas": migração sulista para Rondonópolis -MT. Dissertação de mestrado. UNESP - Presidente Prudente - SP, 2000, 410 p.

GONTIJO, Nicosina Maria Campos. O brilho e a miséria: a exploração de diamantes em Poxoréo-MT (1930-40). Brasília: Fundação Universidade de Brasília, 1988, p. $40-45$.

GOTTDIENNER, Mark. A produção social do espaço urbano. São Paulo: EDUSP, 1993.

HABERMAS, Jurgen. Técnica e ciência como "ideologia". Rio de Janeiro: Edições $70,1994$.

HARVEY, David. Condição pós-moderna. São Paulo: Ed. Loyola, 1992.

LAYRARGUES, Philippe Pomier. A cortina de fumaça: o discurso empresarial verde e a ideologia da racionalidade econômica. São Paulo: Annablume, 1998.

MARCUSE, Herbert. A ideologia da sociedade industrial. Rio de Janeiro: Zahar, 1973.

MARIN, Rosa E. Azevedo et al. Amazônia Oriental: territorialidade e meio ambiente. In: LAVINAS, Lena; CARLEAL, Liana Maria da Frota; NABUCO, Maria Regina (orgs.). Reestruturação do espaço urbano e regional no Brasil. São Paulo: Hucitec, 1993.

MARTINS, Eduardo de Souza; ALHO, Cléber J. R. (editores). De grão em grão, o cerrado perde espaço (cerrado - impactos do processo de ocupação). Brasília-DF: Fundo Mundial para a Natureza, 1995.

MARTINS, José de Souza. Fronteira: a degradação do outro nos confins do humano. São Paulo: Hucitec, 1997.

MONTEIRO, Jorge Luiz Gomes. Mudanças espaciais induzidas pelo progresso técnico: a realidade da agricultura mato-grossense. Tese de doutorado. Rio de Janeiro: Universidade Federal do Rio de Janeiro, Instituto de Geociências, agosto de 2004. 329 p.

MOURA, Sandra Correia. Aspectos da pequena produção em Mato Grosso: o caso de Jaciara e Juscimeira. Dissertação de mestrado. Instituto de Geociências Universidade Federal de Rio de Janeiro, setembro de 1983.

OLIVEIRA, Ariovaldo Umbelino. Integrar para não entregar: políticas públicas e 
Amazônia. Campinas: Papirus, 1991.

OLIVEIRA, Francisco de. Elegia para uma re(li)gião: nordeste, planejamento e conflitos de classe. Rio de Janeiro: Paz e Terra, 1977

PIAIA, Ivone Inez. Geografia de Mato Grosso. Cuiabá- MT: Edunic, 1997.

PINTO, Magda Pereira. A concepção da natureza na esfera ético-filosófica. Dissertação de mestrado. Centro de Estudos Ambientais - UNESP, Rio Claro-SP, 2001.

RAFFESTIN, Claude. Por uma geografia do poder. São Paulo: Ática, 1993.

ROSSO, Gilberto Silva de. Influência da cidade de Rondonópolis na rede urbana da Mesorregião Sudeste Mato-grossense. Dissertação de mestrado. Faculdade de Ciências e Tecnologia - UNESP, Presidente Prudente - SP, 1999.

SILVA, Jovam Vilela. A divisão de Mato Grosso: uma visão histórica. Cuibá-MT: EdUFMT, 1996.

SMITH, Neil. Desenvolvimento desigual. São Paulo: Bertrand, 1988.

SOJA, Edward W. Uma concepção materialista da espacialidade. In: BECKER, Bertha K. et alii (orgs.). Abordagens políticas da espacialidade. Rio de Janeiro: UFRJ, 1983.

SOUZA, Marcelo José Lopes de. O território: sobre espaço e poder, autonomia e desenvolvimento. In: Castro, Iná Elias de; GOMES, Paulo César da Costa; LOBATO, Roberto Correia (orgs.). Geografia: conceitos e temas. Rio de Janeiro: Bertrand Brasil,1995

WEBER, Max. Metodologia das ciências sociais. 4 ed. São Paulo: Cortez, 2001 (Parte 1).

Ciências e política: duas vocações. Tradução de Jean Melvillie. São Paulo: Martin Claret, 2002.

(Recebido em março/2009. Aceito em julho/2009) 